\title{
Pleomorphic Adenoma of Palate- A Case Report with CT and CBCT Features.
}

\author{
Anuraag B. Choudhary ${ }^{1}$, Abhilasha O. Yadav ${ }^{2}$, Mukta B. Motwani ${ }^{3}$, \\ Mayur B.Chaudhary ${ }^{4}$, Shweta M. Chaudhary ${ }^{5}$, Pankaj J. Banode ${ }^{5}$ \\ ${ }^{I}$ Senior Lecturer, Department of Oral Medicine and Radiology, VSPM's Dental College \& Research Centre, \\ Digdoh hills, Nagpur Maharashtra (India). \\ ${ }^{2}$ Reader, Department of Oral and Maxillo-facial Surgery, Sharad Pawar Dental College and Hospital, \\ DMIMSU, Sawangi (M), Wardha Maharashtra (India). \\ ${ }^{3}$ Professor \& Head, Department of Oral Medicine and Radiology, VSPM's Dental college \& research Centre, \\ Digdoh hills, Nagpur Maharashtra (India). \\ ${ }^{4}$ Reader, Department of Oral Pathology and Microbiology, Bharti Vidyapeeth Dental College Pune \\ Maharashtra (India). \\ ${ }^{5}$ Reader, Department of Pedodontia, Bharti Vidyapeeth Dental College Pune Maharashtra (India). \\ ${ }^{6}$ Associate Professor, Department of Radiodiagnosis, AVBRH, co-ordinator TIFAC CORE Cathetrization Lab \\ Sawangi, Wardha Maharashtra (India).
}

\begin{abstract}
Pleomorphic adenoma (PA) can be defined as a benign mixed tumor composed of epithelial and myoepithelial cells arranged with wide cytomorphologic and architectural diversity and morphological patterns, demarcated from surrounding tissues by fibrous capsule. PA is one of the salivary gland tumors affecting both major and minor salivary glands. Parotid gland is the most commonly affected of the major group, and palate is the most common site of the minor salivary glands affected. The tumor has 3 components: an epithelial cell component; a myoepithelial cell component; and a mesenchymal component. The identification of these 3 components, which may vary quantitatively from one tumor to another, is essential to the recognition of pleomorphic adenoma. The tumor is also known as a benign mixed tumor. When these lesions affects the minor salivary glands on palate and if there is any involvement of the surrounding structures like maxillary antrum and nasal floor, then pre-operative imaging of these lesions is mandatory by 3-dimensional imaging modalities like CT or CBCT to evaluate the exact depth and the dimensions of the lesion. Following case of pleomorphic adenoma of palatal salivary glands which was evaluated with CT as well as CBCT preoperatively.
\end{abstract}

\section{Introduction}

Salivary gland tumors are rare; comprising less than $3 \%$ of all neoplasm's of the head and neck region and are known by their complex microscopical features. ${ }^{1,2}$ Pleomorphic adenoma (PA) is the most common salivary gland tumor and represents $60 \%$ to $73 \%$ of the parotid gland tumors, $40 \%$ to $60 \%$ of the submandibular and minor salivary glands tumors. ${ }^{3,4,5}$ It is a benign neoplasm composed of epithelial and myoepithelial cells arranged in a great variety of morphological patterns, with areas of mesenchymal differentiation. ${ }^{6,7}$ Epithelial cells typically form duct-like structures associated with non-ductal cells presenting variable shapes and forms. The stromal element demonstrates varying degrees of myxoid, hyaline, cartilaginous, or osseous differentiation. ${ }^{6}$ Since the tumor is involving primarily the minor salivary glands, it does not show any radiographic features initially when size of the lesion is small. Over a period of time when tumor grows large enough, it may cause pressure resorption and ultimately destruction and perforation of the palatal bone.

Here we present a case of slow growing pleomorphic adenoma of minor salivary glands of palate, which caused pressure resorption and perforation of palatal bone which was well visualized by Cone Beam Computed Tomography (CBCT) technique, which gave an appropriate 3-dimensional images as well as the extent of the lesion alongwith the evidence of palatal perforation in left posterior palatal region.

\section{Case report}

A 56 year female patient visited to the Department of Oral Medicine and Radiology, Sharad Pawar Dental College and Hospital, Sawangi (Meghe), Wardha, Maharashtra, India with the chief complaint of painful slow growing swelling on left posterior part since 1year. Her medical history was non-contributory. She gave history that the swelling had been there for 1 year, but grew slowly in the past 6 months. Intraoral examination (fig. 1) revealed a soft tissue mass $3 \times 3 \mathrm{~cm}$. in greatest diameter at the posterior left side of the hard palate. The oral mucosa covering the lesion was intact and bluish pink in colour. The lesion was rubbery in consistency and 
tender on palpation was observed. The single right submandibular lymph node of size $1 \times 1 \mathrm{~cm}$ was firm mobile and non tender on palpation. Occlusal radiograph revealed (fig. 2) a small $1 \times 1 \mathrm{~cm}$ uniform round radiolucency in 27 and 28 region suggestive of pressure resorption of the palatal bone. Panoramic radiograph (fig. 3) revealed an indistinct left maxillary sinus floor in relation to left maxillary posterior teeth. Aspiration with the wide bore needle yielded a tiny amount of $(0.1 \mathrm{ml}$ aprox $)$ blood tinged serous aspirate from the lesion and on microscopic examination the histopathologic features were suggestive of pleomorphic adenoma. Patient was adviced 3dimensional imaging and CT scan and CBCT imaging was performed. On the 3-D CT of the palate, the lytic erosive lesion of size $13 \times 18.1 \mathrm{~cm}$ noted in relation to $0.5 \mathrm{~cm}$ medial to 26,27 and 28 . Similarly the multiplanar reconstruction (MPR) images (fig. $5 \mathrm{a} \& \mathrm{~b}$ ) revealed the evidence of perforation of the palatal bone by the lesion and the deeper extent of the lesion. The 3-D CBCT image (fig. 6) also revealed the evidence of lytic lesion on left posterior part of hard palate in relation to 26, 27 and 28 region palatally. The MPR images (fig. $7 \mathrm{a}, \mathrm{b}$ and c) revealed the evidence of perforation of palatal bone in all the coronal, axial and sagittal plane. Excisional biopsy of the palatal lesion under general anesthesia was performed and the specimen was sent for histopathological investigation. The histopathological diagnosis was also suggestive of pleomorphic adenoma.

\section{Discussion}

The etiology of pleomorphic adenoma is unknown, however, it has been noted that the incidence increases 15-20 years after exposure to radiation. One study suggests that the simian virus (SV40) may play an etiologic role in the development of pleomorphic adenoma. ${ }^{8,9,10}$ Among the major salivary glands, the tail of the superficial lobe of the parotid salivary gland is the most common site of occurrence (70-80\%), although it can occur in any parotid location. It is less commonly seen in the submandibular salivary gland (10\%) and is seldom encountered in the sublingual gland $(1 \%){ }^{11,}{ }^{12}$ In minor salivary glands $(5-10 \%)$, the palate (specifically, the junction of the soft and hard palates) and the lip are the most common sites. Other sites of minor salivary gland involvement include the nose, the paranasal sinuses, and the larynx. Multiple tumors are unusual $(1: 40,000)$, but metachronous and synchronous tumors do occur. ${ }^{13-16}$

The differential diagnoses for this case include palatal abscess, odontogenic and non-odontogenic cysts, soft tissue tumors and salivary gland tumors. Palatal abscess can be ruled out by clinical examination since the source of palatal abscess which is typically a non-vital tooth in vicinity or a localized periodontal defect was not found. In addition, this patient showed no sign of inflammation. Both odontogenic and non-odontogenic cysts can be ruled out at the time of exploration into the mass since it did not demonstrate cystic nature and also very less amount of aspiration was present. Palatal tissues contain components of soft tissue and harbor minor salivary gland tissues. As a result, soft tissue tumors such as fibroma, lipoma, neurofibroma, neurilemmoma as well as salivary gland tumors should also be considered in the differential diagnoses for this case. The fact that this patient did not exhibit sign and symptom associated with malignant tumor such as ulcer, or paresthesia coupled with a rather slow development of the lesion over 1 year makes the differential diagnosis of malignant lesion unlikely.

Conventional radiographs may stands inadequate in such lesions of palate as there are limitations that it gives two dimensional image of 3-dimensional object. They lack in the accurate extent and depth of the lesion, henceforth the 3-d imaging modalities like CT scan and MRI are considered as gold standard in imaging such lesions. In our case of the PA the lesion was evident as a single radiolucency in posterior left palatal region on occlusal radiograph whereas, panoramic radiograph revealed an indistinct maxillary sinus floor. On CT images the accurate extent and size of the lesion was evident on 3-d as well as in MPR images with palatal perforation. But the disadvantage of the CT scan includes the high radiation exposure, high cost for procedure and CT equipments and more time for exposure. On evaluating the CBCT images the 3-D palatal view, there was evidence of bony erosion similar in pattern to that of CT scan images in same region with accurate extent and perforation as evident on CT scan images. The MPR images of CBCT when evaluated, these images were of similar diagnostic value as that of Computed Tomography scan.

The obvious advantage of the CBCT images was less radiation exposure, less equipment cost and less scan time. Also the image quality 3-D as well as MPR images of the CBCT in this case were much satisfactory to decide the treatment of the case. Thus the CBCT can prove to be an alternative 3-D imaging modality for bony pathology in head and neck where the conventional radiographs proved to be of disappointingly low diagnostic accuracy due to complex anatomy of head and neck region. The treatment of choice for pleomorphic adenoma in minor salivary gland is wide local excision with the removal of periosteum or bone if they are involved. Simple enucleation of this tumor is believed to lead to high local recurrence rate and should be avoided. ${ }^{17}$ 


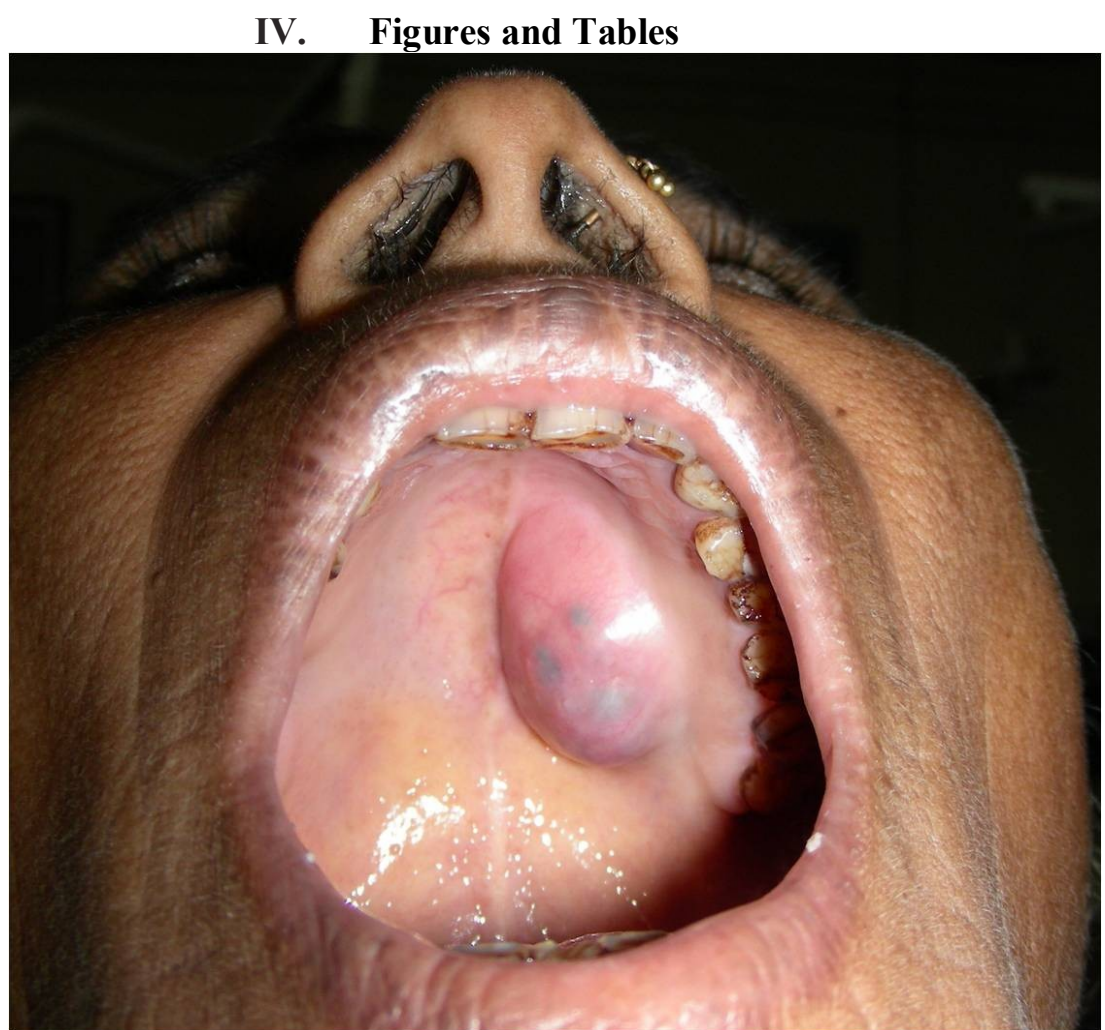

Fig. 1-Intraoral photograph showing dome shaped swelling on left posterior palatal

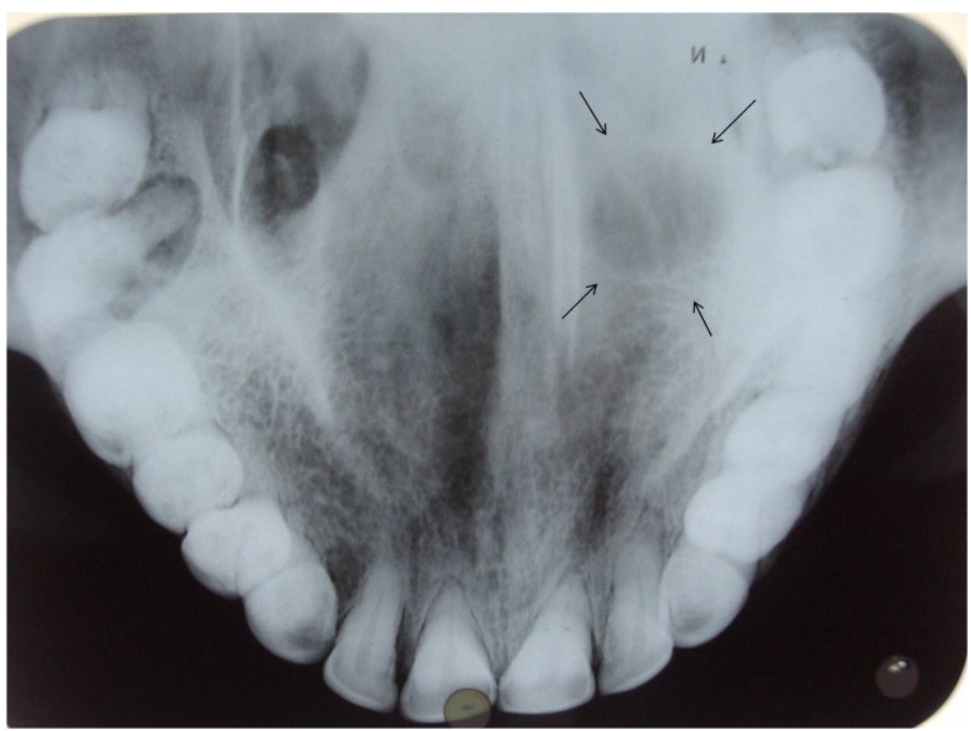

Fig. 2- Occlusal radiograph showing uniform circular radiolucent lesion (arrows) in relation to palatal side of 27 and 26 . 


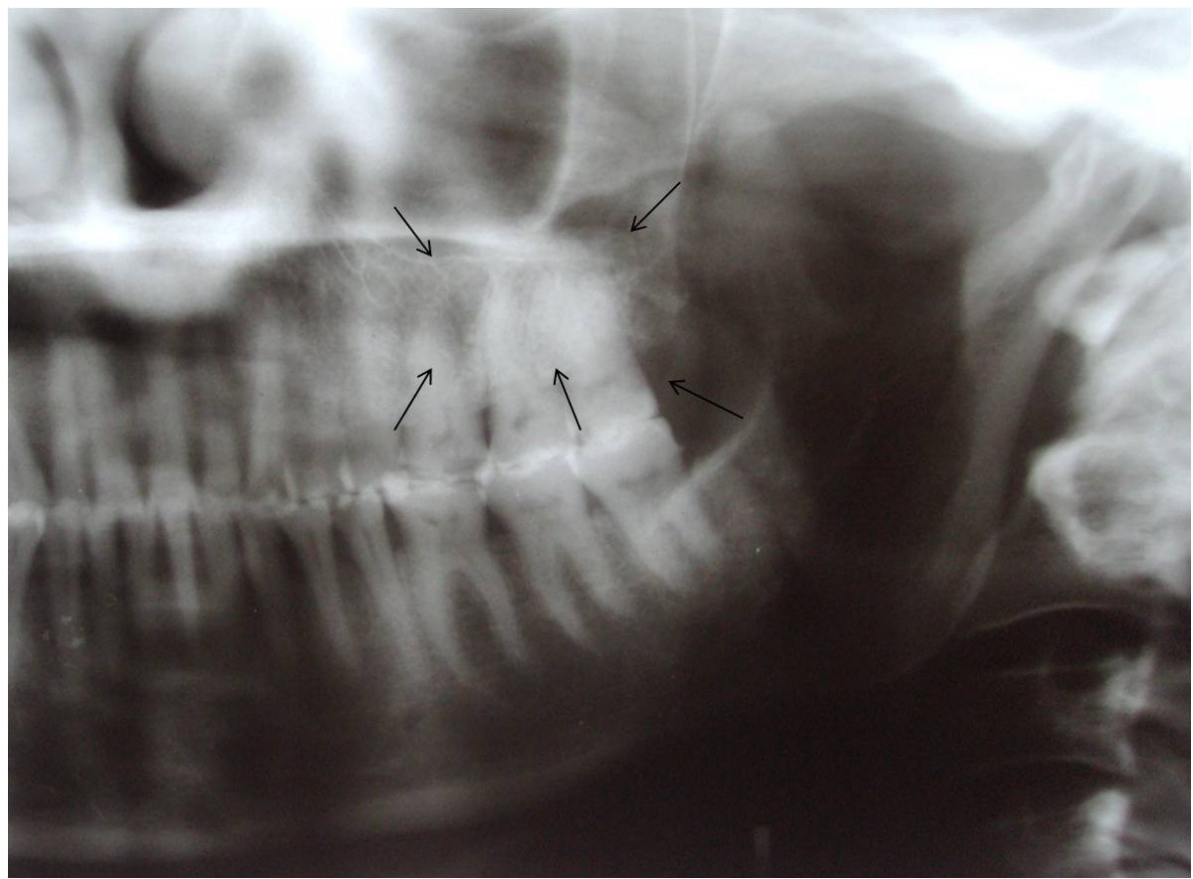

Fig. 3- Cropped panoramic radiograph showing indistinct floor of left maxillary sinus (arrows)

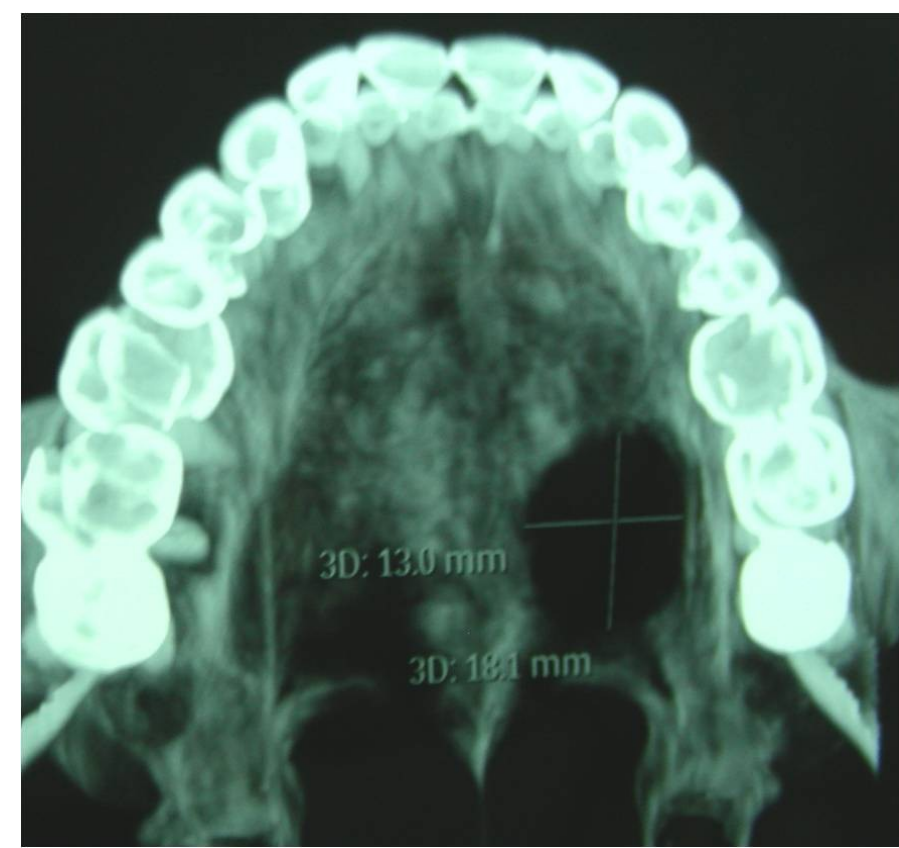

Fig. 4- 3-D CT of hard palate showing erosion of palatal bone with measurement of size 


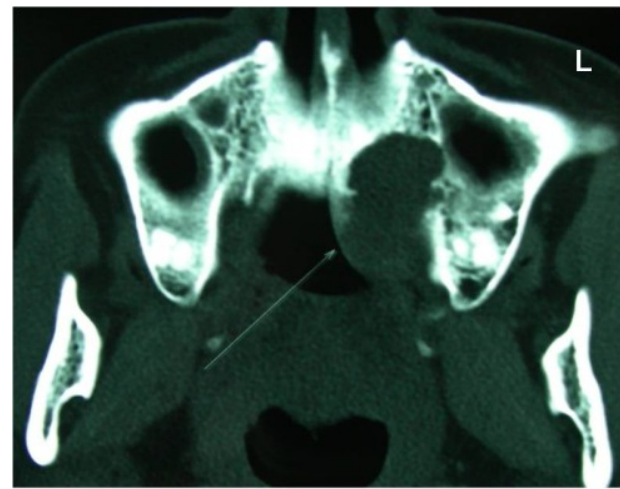

a

b

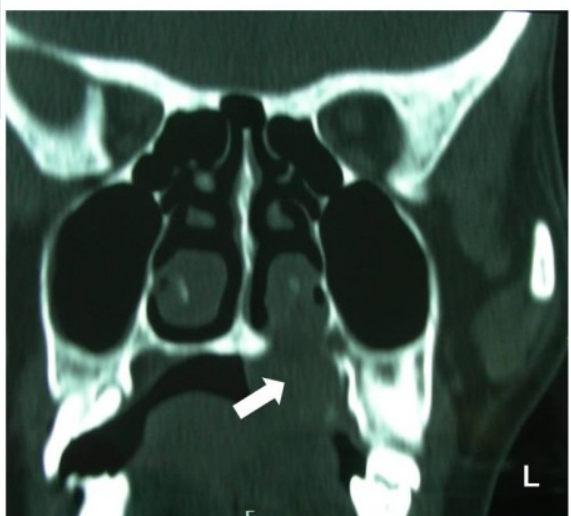

Fig. 5a \& 5b- Coronal and axial CT scan images showing posterior extension and palatal perforation (arrows)

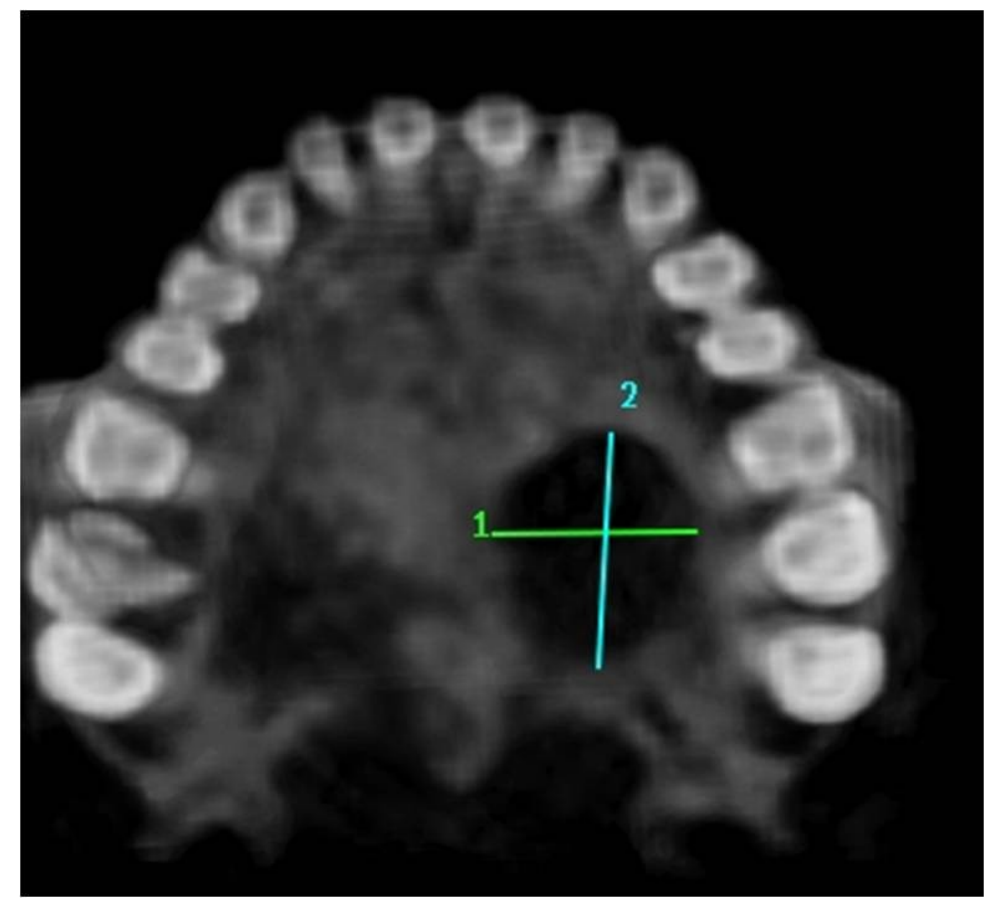

Fig. 6- 3-D CBCT image of palatal bone showing round erosive lesion 


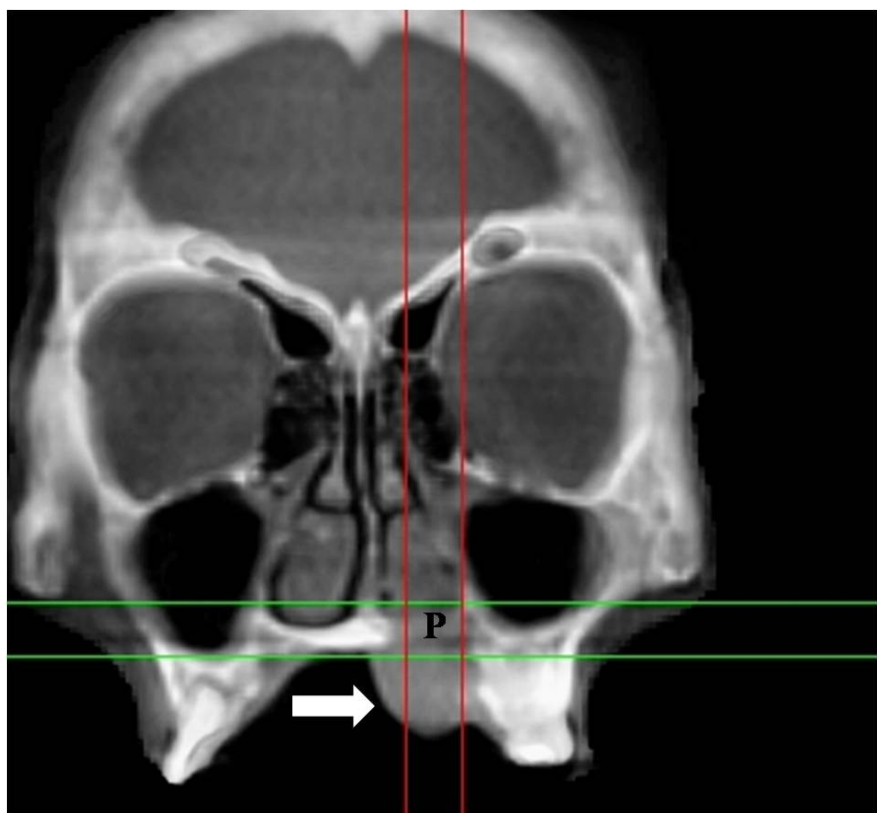

Fig. 7a- coronal CBCT image showing palatal bone perforation and soft tissue shadow of the lesion

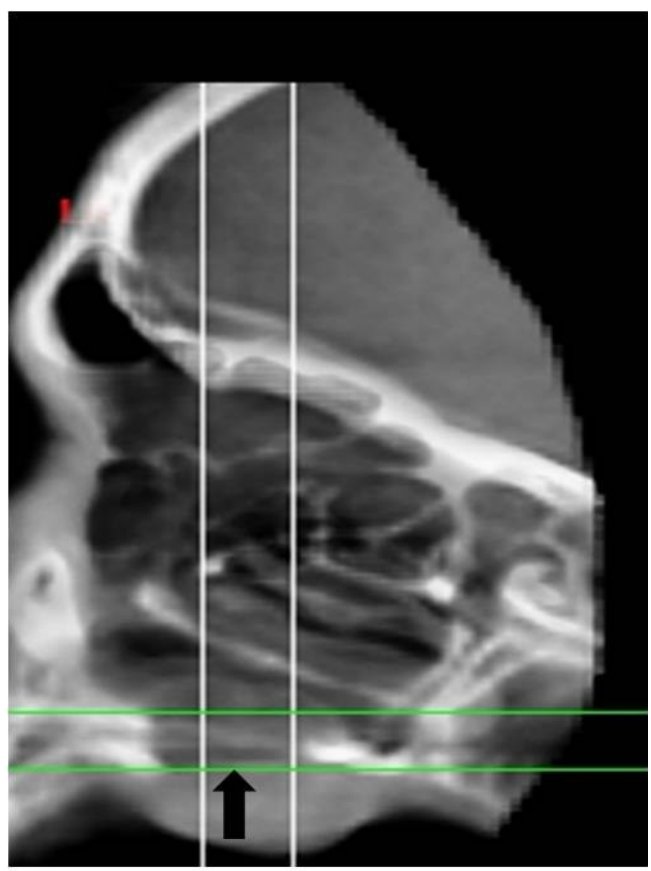

Fig. 7b- axial CBCT image showing uniform round radiolucent lesion (arrow) 


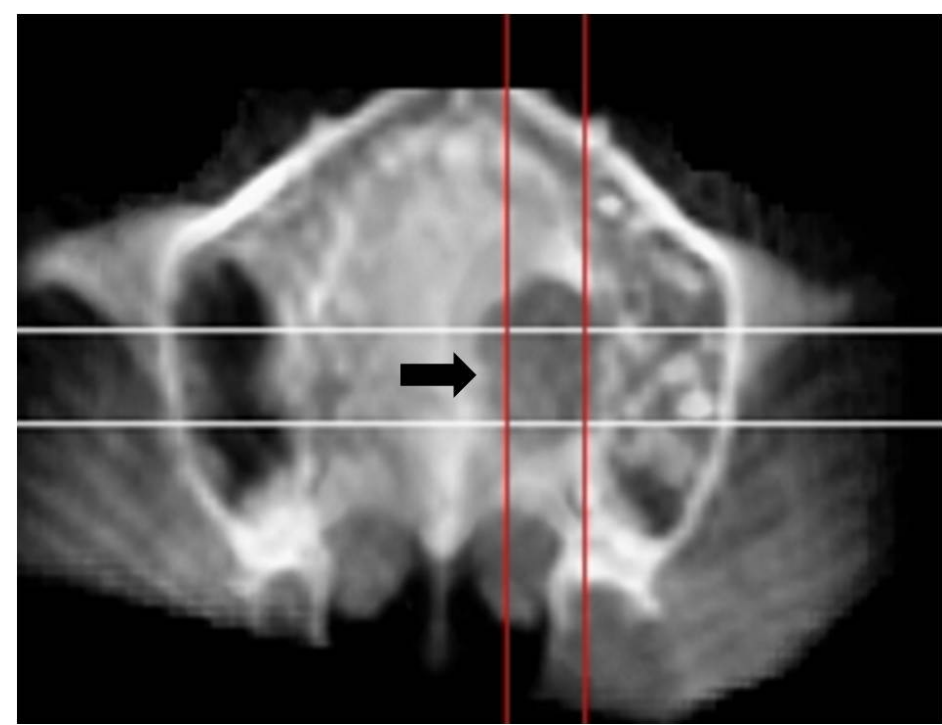

Fig. 7c- sagittal CBCT image showing palatal perforation (arrow)

\section{Conclusion}

The diagnosis of PA was based on clinical, radiographic, FNAC, CT, CBCT and histopathologic features. Also the various recent imaging modalities are available which provides us with the three dimensional images of the complex pathologic lesion in maxilla and mandible, as was done using CT and CBCT in this case. Thus the purpose of this CBCT imaging modality can be satisfactorily good when evaluated appropriately and it can be used as an alternative to CT scan technique for various bony pathologies like cleft, maxillo-facial trauma, implantology, odontogenic cysts and tumors as well as non-odontogenic tumors as well.

\section{Acknowledgment}

We are thankful to Dr. Pankaj J Banode, Mr. Pranay Gawai, technical staff TIFAC (Technology Information, Forecasting Assessment \& Counseling) CORE (Centre of Relevance \& Excellence) in interventional radiology Department of Science and Technology, Acharya Vinoba Bhave Rural Hospital, Sawangi (Meghe), DMIMSU, Wardha, Maharashtra, India supported by Government of India.

\section{References}

[1]. Fabio Augusto Ito, Jacks Jorge, Pablo Agustín Vargas, Márcio Ajudarte Lopes. Histopathological findings of pleomorphic adenomas of the salivary glands. Med Oral Patol Oral Cir Bucal. 2009 Feb 1; 14 (2): 57-61.

[2]. Van der Wal JE, Leverstein H, Snow GB, Kraaijenhagen HA, Van der Waal I. Parotid gland tumors: histologic reevaluation and reclassification of 478 cases. Head Neck. 1998;20:204-7.

[3]. Eveson JW, Cawson RA. Salivary gland tumours. A review of 2410 cases with particular reference to histological types, site, age and sex distribution. J Pathol. 1985;146:51-8.

[4]. Spiro RH. Salivary neoplasms: overview of a 35-year experience with 2,807 patients. Head Neck Surg. 1986;8:177-84.

[5]. Ito FA, Ito K, Vargas PA, De Almeida OP, Lopes MA. Salivary gland tumors in a Brazilian population: a retrospective study of 496 cases. Int J Oral Maxillofac Surg. 2005;34:533-6.

[6]. Ellis GL, Auclair PL. Tumors of the Salivary Glands (Atlas of Tumor Pathology). 3rd series. Fascicle 17. Washington, DC: Armed Forces of Institute of Pathology; 1996.

[7]. Takeda Y. An immunohistochemical study of bizarre neoplastic cells in pleomorphic adenoma: its cytological nature and proliferative activity. Pathol Int. 1999;49:993-9.

[8]. Samir Muhammed Murad. Pleomorphic Adenoma Minor Salivary Gland Tumor Palatal Area. Oral\& Maxillofacial Shifa Hospital. B.Ch.D Alexandria University.

[9]. http//www.emedicine.com/pleomorphic adenoma

[10]. Ellis GL, Auclair PL. Pleomorphic adenoma. In: Ellis GL, Auclair PL. Tumors of the Salivary Glands (Atlas of Tumor Pathology). Facicle 17. Washington, DC: Armed Forces Institute of Pathology; 1996:39-57.

[11]. Alves FA, Perez DE, Almeida OP, Lopes MA, Kowalski LP. Pleomorphic adenoma of the submandibular gland: clinicopathological and immunohistochemical features of 60 cases in Brazil. Arch Otolaryngol Head Neck Surg. Dec 2002;128(12):1400-3.

[12]. Spiro RH. Salivary neoplasms: overview of a 35-year experience with 2,807 patients. Head Neck Surg. Jan-Feb 1986;8(3):177-84.

[13]. Carlsoo B, Ekstrand T. Unilateral multiple mixed tumours of the parotid gland. J Laryngol Otol. Jul 1977;91(7):629-32.

[14]. Gnepp DR, Schroeder W, Heffner D. Synchronous tumors arising in a single major salivary gland. Cancer. Mar 15 1989;63(6):1219-24.

[15]. Sataloff RT, Price DB, Roberts BR. Bilateral synchronous mixed tumors of the parotid glands. Arch Otolaryngol Head Neck Surg. Aug 1987;113(8):880-1.

[16]. Coombes DM, Kaddour R, Shah N. Synchronous unilateral pleomorphic adenomas in the parotid gland: report of a case. Br J Oral Maxillofac Surg. Mar 2009;47(2):155-6.

[17]. Ogata H, Ebihara S, Mukai K. Salivary gland neoplasms in children. Jpn J Clin Oncol. 1994;24:88-93. 